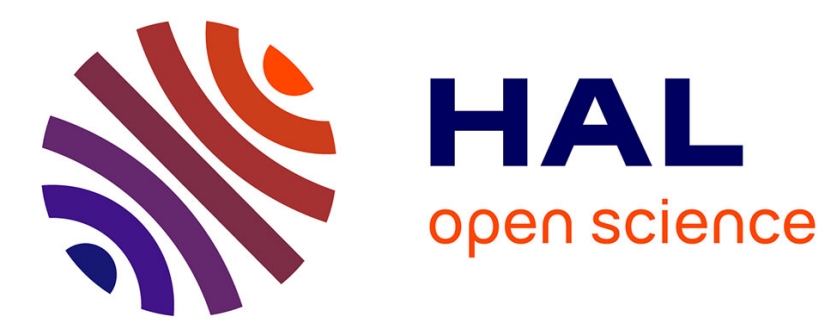

\title{
Experimental investigation of pressure applied on the lower leg by elastic compression bandage
}

Fanette Chassagne, Frédéric Martin, Pierre Badel, Reynald Convert, Pascal Giraux, Jérôme Molimard

\section{- To cite this version:}

Fanette Chassagne, Frédéric Martin, Pierre Badel, Reynald Convert, Pascal Giraux, et al.. Experimental investigation of pressure applied on the lower leg by elastic compression bandage. Annals of Biomedical Engineering, 2015, 43 (12), pp.2967-2977. 10.1007/s10439-015-1352-1 . hal-01251853

\section{HAL Id: hal-01251853 \\ https://hal.science/hal-01251853}

Submitted on 6 Jan 2016

HAL is a multi-disciplinary open access archive for the deposit and dissemination of scientific research documents, whether they are published or not. The documents may come from teaching and research institutions in France or abroad, or from public or private research centers.
L'archive ouverte pluridisciplinaire HAL, est destinée au dépôt et à la diffusion de documents scientifiques de niveau recherche, publiés ou non, émanant des établissements d'enseignement et de recherche français ou étrangers, des laboratoires publics ou privés. 
1 Experimental investigation of pressure applied on the lower leg by

\section{2 elastic compression bandage}

3 Fanette Chassagne*(a)(b) , Frédéric Martin $^{(\mathrm{b})}$, Pierre Badel $^{(\mathrm{a})}$, Reynald

4 Convert $^{(\mathrm{b})}$, Pascal Giraux ${ }^{(\mathrm{c})}$, Jérôme Molimard $^{(\mathrm{a})}$

5 (a) LGF, UMR 5307, École Nationale Supérieure des Mines, CIS-EMSE, CNRS, Saint-

6 Étienne, France

$7 \quad{ }^{(b)}$ Thuasne, BP243, 92307 Levallois-Perret cedex, France

$8{ }^{(c)}$ Department of Physical Medicine and Rehabilitation, Faculty of Medicine, University

9 Jean Monnet, Saint-Etienne, France

$10 *$ Corresponding author. Email: fanette.chassagne@emse.fr 


\section{Abstract}

12 Compression therapy with stockings or bandage is the most common treatment for

13 venous or lymphatic disorders.

14 The objective of this study was to investigate the influence of bandage mechanical

15 properties, application technique and subject morphology on the interface pressure,

16 which is the key of this treatment.

17 Bandage stretch and interface pressure measurements (between the bandage and the leg)

18 were performed on 30 healthy subjects (15 men and 15 women) at two different heights

19 on the lower leg and in two positions (supine and standing). Two bandages were applied

20 with two application techniques by a single operator.

21 The statistical analysis of the results revealed: no significant difference in pressure 22 between men and women, except for the pressure variation between supine and standing 23 position; a very strong correlation between pressure and bandage mechanical properties $24(\mathrm{p}<0.00001)$ and between pressure and bandage overlapping $(\mathrm{p}<0.00001)$; a significant 25 pressure increase from supine to standing positions $(\mathrm{p}<0.0001)$. Also, it showed that 26 pressure tended to decrease when leg circumference increased.

27 Overall, pressure applied by elastic compression bandages varies with subject 28 morphology, bandage mechanical properties and application technique. A better 29 knowledge of the impact of these parameters on the applied pressure may lead to a more 30 effective treatment.

32 Keywords: compression bandage, pressure measurements, pressure variation, bandage 33 application technique, bandage mechanical properties, subject morphology, venous and 34 lymphatic disorders 


\section{Introduction}

36 Compression bandage is a common treatment for venous or lymphatic pathologies such

37 as venous ulcers or lymphedema. In such diseases, bandages are preferred in the first

38 step of the treatment by compression, instead of stockings. Indeed, during the first days

39 of the treatment, the patients' leg shape changes a lot and the same compression

40 bandage can be applied on the leg with different geometries, whereas a new stocking size would be needed to accommodate these changes. Once the leg shape is stable, the treatment by compression is usually performed with socks or stockings. Bandages are also used when the patient's pathology prevents the use of any other treatment (for example after a knee arthroplasty). Moreover, it is easier for a caregiver to apply bandages than stockings on patients' legs, especially with patients with impaired mobility. Consequently, compression bandage and stockings are complementary.

47 The bandage, tight on the limb, applies a pressure on the external surface of the limb which is then transmitted to the internal tissues and to the veins ${ }^{1,2}$. Numerous studies have proven the effect of compression therapy on venous and lymphatic system ${ }^{3-5}$, whether compression is performed with bandage or stockings ${ }^{6}$.

The efficacy of the treatment mainly depends on the level of pressure which is applied on the limb ${ }^{7,8}$. This level of pressure depends on several parameters such as:

- The bandage mechanical properties

- $\quad$ The bandage components (padding layer, cohesive bandage, ...)

- The bandage stretch

- The local curvature of the limb on which the bandage is applied properties of the limb soft tissues, ... 
60 Better understanding how these parameters impact the level of applied pressure would

61 lead to an improved treatment with compression bandage.

62 A well-known theoretical relationship between the tension, $\mathrm{T}$, of the bandage (force

63 needed to stretch the bandage, which is given by the bandage mechanical properties and

64 the applied stretch), the local curvature, $r_{c}$, of the limb and the locally applied pressure,

$65 \mathrm{P}$, is given by the Laplace's Law:

$$
P=T / r_{c}
$$

66 However, it has been shown that this law is not sufficient to explain the pressure

67 distribution over a limb ${ }^{9,10}$, hence the need for an experimental investigation of the

68 pressure applied by compression bandage on the lower leg.

69 Several measurements of the pressure applied by bandages were carried out, with 70 various types of bandages, at different measurement points and on a wide range of 71 subjects in different body positions ${ }^{11-13}$. In order to standardize the way to perform 72 pressure measurements, recommendations have been published to proceed to interface 73 pressure measurements ${ }^{8}$. Measurement points have been identified on the lower leg ${ }^{8}$ 74 such as (Figure 1):

75 - Measurement point B1: corresponding to the height where the Achilles' tendon turns into the gastrocnemius muscle.

- Measurement point C: corresponding to the height where the calf circumference is the largest.

The pressure sensors used for the measurements should meet some requirements: for 80 example to be thin and flexible ${ }^{8}$. Different types of sensors exist but some have proven 81 to be more reliable than others ${ }^{14}$ (Kikuhime ${ }^{\circledR}$ and Picopress ${ }^{\circledR}$ for example).

82 Most of the measurement campaigns which were performed on men and women did not 83 take the gender difference into account ${ }^{13,15}$. However the leg morphology has an 
84 influence on the applied pressure. Indeed, the leg morphology varies from a subject to

85 another and maybe even more especially from a female subject to a male subject ${ }^{16}$.

86 Other groups investigated the impact of the application technique on the interface

87 pressure ${ }^{17}$ and they also measured the stretch of the applied bandage. However, as the

88 aim of this previous study was to compare the pressure applied by different application

89 techniques, it was carried out for a single bandage type. Other studies were focused on

90 the influence of bandage mechanical properties and position (supine, standing, sitting)

91 on the interface pressure ${ }^{12,18-20}$, but as far as we know, none of them measured the

92 stretch of the applied bandage, though it is one of the main parameters which controls

93 the interface pressure.

94 This shows the need of performing other pressure measurements in order to 95 simultaneously evaluate the influence of all following parameters on the interface 96 pressure: bandage mechanical properties, application technique, subjects' gender and 97 morphology and position (supine or standing).

98 Within this context, the objective of the present study is to perform a complete 99 campaign including bandage stretch and pressure measurements in order to test the 100 following hypotheses:

101 - The applied pressure is proportional to the bandage elastic modulus (or the force needed to stretch the bandage)

103 - The applied pressure is proportional to the bandage overlapping (50\% or $66 \%$ 104 overlapping means that respectively 2 or 3 bandage layers cover the leg)

105 - The interface pressure significantly decreases when the subjects' leg $106 \quad$ circumference increases.

107 Moreover, these measurements result to a quantitative evaluation of the pressure 108 differences among female and male subjects and of the pressure increase between the 
supine and the standing position.

\section{Methods}

111 Briefly, stretch and pressure measurements were performed on healthy male and female

112 subjects in order to estimate the gender influence. Subjects were chosen in order to have

113 a wide range of morphologies. Two different elastic bandages, with different

114 mechanical properties, were applied on the subject's leg with two application

115 techniques with the aim of evaluating the influence of mechanical properties,

116 application technique and position (supine or standing) on the interface pressure.

\section{$117 \quad 2.1 \quad$ Bandages}

118 Two commercially available elastic bandages, which differ in their mechanical 119 properties, were applied on the subjects' leg by the same experienced operator: the 120 Biflex ${ }^{\circledR} 16$ (B16) and the Biflex ${ }^{\circledR} 17$ (B17) (Thuasne, Levallois-Perret, France) which is

121 stiffer (Table 1). Bandage elastic modulus (K), in N/mm, is defined as follows:

$$
K=\frac{\text { Force to stretch the bandage }}{\text { bandage width } *\left(L-L_{0}\right) / L_{0}}
$$

122 where $L$ is the length of the stretched bandage and $L_{0}$ its initial length (Figure 2). Both

123 bandages were $10 \mathrm{~cm}$ wide. They were applied on the leg with a target stretch of 1.3 , in

124 accordance with the manufacturer's recommendations and visual calibration marker

125 (Figure 2). This visual calibration marker is a rectangle which turns into a square when

126 the bandage stretch is equal to 1.3. It gives a visual indication to the bandager that the

127 stretch is in accordance with the manufacturer's recommendations. The stretch is

128 defined as the ratio between the length of the stretched bandage and its initial length

129 (stretch $\left.=L / L_{0}\right)$. Bandage can be applied in the form of a spiral with a $50 \%$ or a $66 \%$

130 overlap, which means that at each turn, the bandage layer on top covers the bandage 
131 layer below respectively by $50 \%$ or $66 \%$ (Figure 2 and Figure 3). For a $50 \%$ or $66 \%$

132 overlapping technique, the leg is covered by respectively 2 or 3 bandage layers. The

133 value of the overlap is usually prescribed by medical doctors. Lines were drawn on the

134 bandage to help the bandager to apply the bandage with the correct overlap: one at 50\%

135 and one at $33 \%$ of the bandage width, for respectively a $50 \%$ and a $66 \%$ overlapping

136 technique (Figure 2).

\section{$137 \quad 2.2 \quad$ Pressure sensors}

138 The interface pressure was measured with pneumatic pressure sensors Picopress ${ }^{\circledR}$

139 (MicroLab Elettronica, Ponte S. Nicolo, Italy). This pressure sensor is a convenient

140 device which was used in several previous pressure measurements studies ${ }^{11,21,22}$.

141 As a preliminary study, the accuracy, the linearity and the hysteresis of the sensors were

142 tested. To achieve this, the sensor was placed at the bottom of a water column. First, the

143 column was filled with water and a measure was taken every $10 \mathrm{mmHg}\left(13.6 \mathrm{cmH}_{2} \mathrm{O}\right)$

144 from 0 to $147 \mathrm{mmHg}\left(199.9 \mathrm{cmH}_{2} \mathrm{O}\right)$. Then the column was emptied and a measure was

145 taken every $10 \mathrm{mmHg}$. This allowed characterizing the hysteresis of the sensor, which is

146 given by the following equation:

$$
E_{h}=\operatorname{mean}_{x_{i}}\left(\frac{\left|y_{+}\left(x_{i}\right)-y_{-}\left(x_{i}\right)\right|}{x_{i}} * 100\right)
$$

147 where, $y_{+}\left(x_{i}\right)$ and $y_{-}\left(x_{i}\right)$ are the measured pressure value for a theoretical applied

148 pressure equal to $x_{i}$, respectively during the loading and the unloading phases. The

149 second test consisted in applying 20 different pressure values, which were randomly

150 determined and allowed characterizing the sensor linearity. The coefficient of 151 determination $\mathrm{R}^{2}$ was used as the indicator of the linear dependence between the 152 theoretical and the measured pressure. The closer to 1 the coefficient $\mathrm{R}^{2}$ was, the more 153 linear the sensor was. 
154 These tests were performed for the Picopress ${ }^{\circledR}$ device and the two sensors which were

155 used in the study (respectively at measurement points B1 and C).

156 The tests showed that $\mathrm{R}^{2}$ was almost equal to 1 for both sensors $\left(\mathrm{R}^{2}=0.9999\right)$ and that

157 the hysteresis was slightly higher for the sensor located at measurement point B1 (1.0\%)

158 than for the other sensor located at measurement point $\mathrm{C}(0.0 \%)$.

159 The tests performed on the sensors showed that these sensors were very reliable and,

160 hence, suitable for the present work, which was in accordance with the tests conducted

161 by Partsch et al. ${ }^{14}$.

$162 \quad 2.3 \quad$ Experimental protocol

\section{Subject selection}

164 Pressure measurements were carried out on 30 healthy subjects, 15 women and 15 men,

165 following informed consent (Table 2). This protocol was approved by the local ethics 166 committee.

167 The subjects' selection was made with regards to their circumference at measurement 168 point B1 (Figure 1) in order to be equally distributed in 3 groups of circumference at B1 169 height.

170 For this, a list of 205 women and one of 147 men were built and alphabetically ordered.

171 Six groups (three for women and three for men) were created, depending on the 172 subjects' circumference at measurement point B1:

$173-$ Circumference $\leq 29 \mathrm{~cm}$

$174-$ Circumference $>29 \mathrm{~cm} \mathrm{\&}<32 \mathrm{~cm}$

$175-$ Circumference $\geq 32 \mathrm{~cm}$.

176 Then 5 subjects were randomly selected in each group. The only criteria for subject

177 selection were their gender and their circumference at point B1. 
178 Once the subjects were chosen, the order in which they would take part in the study was

179 randomly determined.

180

181

182

183

184

185

186

187

188

189

190

191

192

193

194

195

196

197

198

199

\section{Pressure measurements}

Two sensors were positioned on the medial side of the right leg at heights corresponding to the measurement points B1 and $\mathrm{C}$ (Figure 3). Measurement point B1 was chosen following the recommendations of a consensus paper on interface pressure measurements ${ }^{8}$ and measurement point $\mathrm{C}$ was chosen because it corresponds to a part of the calf which is mainly composed of soft tissues. All bandages were applied by the same trained operator. Four types of bandages were applied in the form of a spiral (Figure 3):

- B16 with a 50\% overlap (B16 - 2 layers)

- $\quad$ B16 with a $66 \%$ overlap (B16 - 3 layers)

- $\quad$ B17 with a 50\% overlap (B17 - 2 layers)

- $\quad$ B17 with a $66 \%$ overlap (B17 - 3 layers).

The order in which the bandages were applied was randomly determined for each subject.

The bandage was applied in the supine position, after a rest time of 5 to 10 minutes (time needed to set the sensors on the subject leg). Immediately after the bandage application, the stretch of the bandage around the measurement points B1 and C was measured thanks to a mark printed on the bandage every $100 \mathrm{~mm}$ (Figure 2). The distance between three consecutive marks (initially equal to $200 \mathrm{~mm}$ ) was measured using a measuring tape once the bandage had been applied on the leg, around the locations of measurement points $\mathrm{B} 1$ and $\mathrm{C}$, providing the stretch of the bandage (for example, if the distance was equal to $252 \mathrm{~mm}$, the stretch of the bandage at this location was $252 / 200=1.26)$. 
203 After bandage application, the subject waited for two minutes in the supine position

204 with the foot slightly raised in order to prevent any contact between the calf and the

205 examination bed. After this time, three successive measurements were acquired. The

206 mean value of the three measurements was considered as the pressure value.

207 Then the subject was asked to stand up and waited for 2 minutes before the measures

208 were taken again.

$209 \quad 2.4 \quad$ Statistical analysis

210 For all results, the values are given with their $95 \%$ confidence interval and all

211 histograms represent the mean value and the 95\% confidence interval.

212 Parametric tests (analysis of variance (ANOVA)) were used to evaluate all difference

213 between two samples (whose size $n \geq 30$ ), except to analyse the effect of circumference

214 on the pressure (the samples were too small: $\mathrm{n}<30$ ).

215 For the small samples $(\mathrm{n}<30)$, the Kruskal-Wallis one-way analysis of variance was

216 used and then the individual effects were tested with a Mann-Withney $\mathrm{U}$ test ( $\alpha=$

$\left.217 \frac{0.05}{\text { number of tests }}\right)$.

218 To evaluate the linear correlation between two samples, the coefficient of determination

$219 \mathrm{R}^{2}$ was computed, which equals the square of the Pearson correlation coefficient

220 between the experimental data and the values from the linear regression. The variable $t$,

221 which is approximately distributed as a Student's distribution with $n-2$ degrees of

222 freedom for a zero correlation, was used to test the significance of the coefficient of

223 determination $\mathrm{R}^{2}: t=\sqrt{R^{2} * \frac{n-2}{1-R^{2}}}$.

224 The coefficient of determination was used to characterize the linear correlation between

225 the following parameters:

226 - the pressure applied by a B16 and the one applied by a B17 
- $\quad$ the pressure applied by 2 layers and the one applied by 3 layers

- the pressure at measurement point $\mathrm{B} 1$ and the one at point $\mathrm{C}$

229

- the pressure in the supine position and the one in the standing position.

230 Difference was considered as significant if $\mathrm{p}<0.05$.

\section{$231 \quad 3 \quad$ Results}

\subsection{Bandage Stretch}

233 Considering all bandages together, mean stretch was equal to $1.30 \pm 0.007$, in 234 accordance with the manufacturer's recommendations (Figure 4 - a). However, the

235 results demonstrated that, irrespective of bandage type (B16 or B17), stretch at point B1

236 was significantly lower $(\mathrm{p}<0.0001)$ than at point $\mathrm{C}$. Mean stretch at point B1 was lower 237 than recommended $(1.27 \pm 0.009)$. Conversely, at point $\mathrm{C}$, mean stretch was higher 238 than recommended $(1.33 \pm 0.008)$.

239 Also, B17 was applied with a significantly lower stretch than B16 ( $<0.03)$, 240 respectively $1.29 \pm 0.009$ and $1.31 \pm 0.01$

241 No significant difference in stretch was observed at point $\mathrm{C}$ between bandage applied

242 with $50 \%$ and $66 \%$ overlapping. Conversely, at point B1, bandages applied with $66 \%$ 243 overlapping exhibit higher stretch compared to bandages applied with 50\% overlapping $244(\mathrm{p}<0.002)$, respectively $1.29 \pm 0.012$ and $1.26 \pm 0.012$

\subsection{Pressure values for the different bandages}

246 Considering all bandage types, body positions and measurement points, interface

247 pressure increased significantly $(\mathrm{p}<0.0001)$ with bandage overlapping. Interface

248 pressure applied by bandage with $66 \%$ overlap were higher than pressure applied by 249 bandage with $50 \%$ overlap (Figure 4 - b). Similarly, interface pressure increased 
250 significantly $(\mathrm{p}<0.0001)$ with bandage elastic modulus: pressures applied by B17 were

251 higher than pressures applied by B16 with the same application technique.

252 There was no significant difference $(p>0.05)$ between interface pressure measured with

253 B16 applied with 3 layers and B17 applied with 2 layers.

\section{$254 \quad 3.3 \quad$ Gender influence}

255 There was no overall significant difference between male and female in terms of 256 pressure values and pressure gradient $(\mathrm{p}>0.05)$.

257 However, pressure variations between supine and standing positions were significantly 258 different between male and female $(\mathrm{p}<0.01)$. These variations were higher for males 259 irrespective of bandage type and measurement point but the difference between sex

260 remained low: the pressure variations between the two positions were $+11 \%$ for women 261 and $+14 \%$ for men.

\subsection{Influence of bandage mechanical properties}

263 The correlations between the pressures exerted by the B16 and the B17 were significant

264 at all measurements points, in all positions and for both application techniques $265(\mathrm{p}<0.0001)($ Figure $5-\mathrm{a})$. The pressure exerted by the B17 was about 1.5 times as high

266 as the pressure exerted by the B16 whereas the ratio of elastic moduli was 1.

267 95.Influence of application technique

268 The correlation between the pressures exerted by any bandage applied with $66 \%$

269 overlap and the same bandage applied with $50 \%$ overlap was significant at all 270 measurement points and in all positions $(\mathrm{p}<0.01)$ (Figure $5-\mathrm{b})$. 


\subsection{Influence of measurement point (degressivity)}

272 The results demonstrated that, irrespective of bandage type, application method and

273 body position, the elastic bandages followed the principle of pressure gradient along the

274 length of the limb (Figure $5-\mathrm{c}$ ). The measured pressures decreased significantly

$275(\mathrm{p}<0.0001)$ from point $\mathrm{B} 1$ to point $\mathrm{C}$, which means that bandages are degressive

276 (decreasing pressure from the ankle to the knee). Pressures measured at point B1 were

277 about $7 \%$ higher than pressures measured at point $\mathrm{C}$.

278

279

280

281

282

283

284

285

286

287

\subsection{Influence of position}

The interface pressure increased significantly $(\mathrm{p}<0.0001)$ from the supine position to the standing position, at point $\mathrm{B} 1$ and at point $\mathrm{C}$, irrespective of bandage type and application method (Figure 5 - d). On average, interface pressures in standing position were $12 \%$ higher than in supine position.

\subsection{Pressure and circumference}

Irrespectively of bandage type, application method and body position, interface pressures tended to decrease when circumference at measurement point B1 increased (Figure 6). Differences were always significant $(\mathrm{p}<0.05)$ between circumferences at B1 below $29 \mathrm{~cm}$ and over $32 \mathrm{~cm}$.

\section{Discussion}

The main strength of the study is to provide a unified investigation of the influence of several parameters on the applied pressure. It quantifies the influence of parameters which were usually not taken into account. Among the most significant results, it was shown with our measurements that the bandage stretch is the key to a better control of the treatment. This data should be provided and considered in every future study on 
compression bandages. It was also shown that the relationship between applied pressure

295 and elastic modulus of the bandage is not linear, which disputes once again Laplace's

296 law in the context of compression bandages.

297 The objective of the present study was to perform a complete campaign of stretch and

298 interface pressure measurements carried on 30 subjects in order to test the following

299 hypotheses:

300 - Hypothesis 1: the applied pressure is proportional to the bandage elastic $301 \quad$ modulus

302 - Hypothesis 2: the applied pressure is proportional to the bandage overlapping

303 - Hypothesis 3: the interface pressure significantly decreases when the subjects' $304 \quad$ leg circumference increases.

305 All bandages were applied by the same trained operator and the stretch of the applied 306 bandage was close to the manufacturer's recommendations. It was noticed, however,

307 that the actual stretch was not constant over the leg and was influenced by the bandage 308 mechanical properties. It was shown that the interface pressure proportionally increased 309 with the elastic modulus (Hypothesis 1) and the overlapping (Hypothesis 2) of the 310 bandage and that it tended to decrease when the leg circumference increased 311 (Hypothesis 3). Moreover, no significant difference was observed between men and 312 women except for the pressure increase between the supine and standing position, 313 which was larger for men. These results lead to a more detailed analysis of the 314 quantified respective influence of the different parameters on the interface pressure, 315 hence an improved understanding of the treatment. The following discussion is 316 structured around three topics: the bandage itself, the subject and its position. 
318 Even though the bandage stretch greatly impacts the level of interface pressure, it was

319 noticed in previous studies ${ }^{23,24}$ that the bandage tension varied a lot with the bandager,

320 even for experienced bandager. However each bandager seemed to be constant and

321 repeatable in applying bandages ${ }^{25,26}$. In this study, all bandages were applied by one

322 trained bandager. This is why the observed trends only reflect one bandager's

323 application technique and cannot be generalized straightaway.

324 Nevertheless, the maximum, minimum and mean stretches (respectively 1.45, 1.18 and

325 1.30) measured in the present study were in the vicinity of the target value of 1.3 . This

326 showed that the calibration marker (a rectangle which turns into a square when the

327 stretch is equal to 1.3 (Figure 2) was effective in having a bandage stretch close to 1.3

328 . However, the stretch was not constant over the leg, with larger stretch at point $\mathrm{C}$ than

329 at point B1, suggesting an influence of the leg's diameter on the bandager application

330 technique. Moreover, the stretch was larger for the B16 than for the B17, which could

331 be explained by the fact that the B16 was less stiff, so was easier to stretch, thus

332 providing a different feedback to the operator. Measuring the stretch has shown that its

333 control during bandage application can still be improved.

335 The results revealed a very strong correlation between the pressure and the bandage

336 mechanical properties $(\mathrm{p}<0.00001)$. The ratio between the pressure exerted by the B17

337 and that exerted by the B16 was about 1.5. This result raised an important question.

338 Indeed, the ratio between the forces necessary for a 1.3 stretch was equal to 1.95 (force

339 for the B16 $=0.069 \mathrm{~N} \cdot \mathrm{mm}^{-1}$; force for the B17 $=0.0135 \mathrm{~N} \cdot \mathrm{mm}^{-1}$ ), which should induce

340 a ratio of 1.95 in pressure according to Laplace's Law as the pressure is supposed to be

341 directly proportional to the force needed to stretch the bandage. Even though the

342 measured stretch was lower for the B17 than for the B16, the relative difference in the 
343 stretch $(1.3 \pm 0.9 \%$ of the stretch $)$ is not sufficient to explain the difference between

344 the experimental ratio $(1.48, \mathrm{p}<0.00001)$ and the expected ratio $(1.95)$, as this ratio is

345 equal to 1.93 considering the slight difference in stretch. It is hypothesized that this

346 difference is due to friction between the bandages and/or the application gesture.

347 However, these are complex phenomena and need to be further investigated.

348 This study highlighted a strong correlation between the interface pressure and the 349 bandage overlapping $(\mathrm{p}<0.00001)$. The impact of the application technique on the 350 pressure seemed to be in accordance with what was expected. Indeed, the ratio between 351 the pressure applied by a 3-layer bandage and the one applied by a 2-layer bandage 352 should be equal to $3 / 2=1.5$. The experimental ratio was about $1.5(\mathrm{p}<0.00001)$, which 353 is in accordance with the theory.

The second group of parameters which impacts the interface pressure is directly related to the subjects: their gender and morphology. In this study, pressure measurements were performed on both men and women subjects and the only significant difference between these two populations was for the pressure increase between the supine and the standing position. However the results were not treated separately for men and for women because it has been considered that the difference (3\% of the pressure values) was small

361 enough to merge the results. Nonetheless, it may be hypothesized that this small 362 difference is due to the difference in musculature between men and women, which leads 363 to a difference in the geometry variation between the supine and the standing position.

365 Considering both populations altogether, it was showed that the pressure tended to 366 decrease when the leg circumference increased, which is in general agreement with the 367 Laplace's law, as the pressure is supposed to be inversely proportional to the radius of 
curvature. Also, the circumference at point $\mathrm{C}$ was larger than the circumference at point

369 B1, hence the fact that the bandage was degressive (the pressure at point B1 is higher than the pressure at point C). However, in the Laplace's law, only the local radius of

371 curvature has an influence of the pressure. A larger circumference is only the sign of a

372 global radius estimate but it does not consider local radius values. In that sense, our

373 results showed that the level of pressure can vary significantly from a subject to another

374 and that it depends on their leg geometry.

375

376 Eventually, the impact of the subject position was investigated: the pressure increased

377 when moving from the supine to the standing position. Due to gravity, the leg geometry

378 changes from the supine to the standing position (Figure 7). The bandage is applied in

379 the supine position. After bandage application, when the subject stands up, the leg

380 circumference tends to increase ${ }^{28}$, which leads to an increase in the bandage stretch and

381 induces a pressure increase. This change in geometry from the supine to standing

382 positions may be a consequence of the muscle group tendency to fall down (because of

383 gravity) and of the increase of hydrostatic blood pressure. The observed pressure

384 difference can be used to characterize the stiffness of the bandage as described in the

385 literature ${ }^{29}$. In this study, for which elastic bandages were used, the pressure increase is

386 equal to $6.10 \pm 0.54 \mathrm{mmHg}$. This is in accordance with the previous classification

387 given by Partsch et al. ${ }^{30}$, where elastic bandages should display an increase below 10

$388 \mathrm{mmHg}$.

\section{Limitations}

390 The subjects in this study were all healthy subjects whose mean age was lower than the

391 mean age of pathologic patients using compression bandage. An interesting perspective

392 will be to carry out the same measurements on pathologic subjects. Moreover, the 
393 pressure measurements were performed almost right after the bandage application,

394 therefore neglecting the behavior of compression bandage over time (slipping of the

395 bandage, pressure loss, ...). Also, all measurements were static measurements.

396 All the tests that have been performed on the sensors were performed on a flat surface

397 whereas they were used on a curved surface. This type of sensor was already tested on

398 curved surface and showed some imprecisions: they tend to slightly overestimate

399 pressure values ${ }^{31}$. However, the largest radius of curvature used in this study was 55

400 mm whereas the approximated radius of curvature of the limbs in this study went from

40140 to $70 \mathrm{~mm}$ (for measurement points B1 and C). The influence of curvature on the

402 pressure measured by Picopress, in the range of limb curvature, should be further

403 investigated.

404 Moreover, an on-going work aims to study the modification in the radius of curvature 405 due to the sensor. Indeed, even though its thickness is very small, its $2 \mathrm{~mL}$ volume may 406 induce a local variation in the radius of curvature, which may affect the local value of 407 interface pressure.

408 All bandages were applied by the same person in order to prevent large variations in the

409 bandage application. However, it would have been interesting to evaluate the variation 410 in the application between different bandagers.

\section{Conclusion}

412 This study aimed at an objective evaluation of the influence of bandage mechanical 413 properties, application technique and subject morphology on the interface pressure 414 applied on the lower leg by elastic compression bandages and the influence of these 415 parameters on the stretch actually applied by the bandager. It has revealed a very strong 416 correlation between the applied pressure and the bandage mechanical properties but also

417 between the pressure and the application technique. In a previous study ${ }^{29}$, H. Partsch 
418 has raised the question of the control of the application technique and our study

419 corroborates this claim. A better control of the stretch and the application technique will

420 lead to a better control of the pressure applied by compression bandages. This study also

421 shows the limit of the Laplace's law in explaining the level of interface pressure and

422 raises some questions about parameters which have not been taken into account yet,

423 such as the friction between the bandage layers. An interesting future direction will

424 address dynamic measurements of the pressure applied by a single compression

425 bandage or the superimposition of 2 compression bandages. These measurements could

426 be performed on pathologic subjects.

427 Conflict of interest

428 Thuasne is a compression bandage manufacturer. 
430 1. Partsch B, Partsch H. Calf compression pressure required to achieve venous closure from supine to standing positions. J Vasc Surg. 2005;42(4):734-738.

432

433

434

435

436

437

438

439

440

441

442

443

444

445

446

447

448

449

450

451

452

453

454

455

456

457

458

459

460

461

462

463

464

465

466

467

468

2. Rohan P-Y, Badel P, Lun B, Rastel D, Avril S. Prediction of the Biomechanical Effects of Compression Therapy on Deep Veins Using Finite Element Modelling. Ann Biomed Eng. 2015;43(2):314-324.

3. Agu O, Hamilton G, Baker D. Graduated compression stockings in the prevention of venous thromboembolism. Br J Surg. 1999;86(8):992-1004.

4. O’Meara S, Cullum N, Nelson EA, Dumville JC. Compression for venous leg ulcers. In: The Cochrane Collaboration, O'Meara S, eds. Cochrane Database of Systematic Reviews. Vol Chichester, UK: John Wiley \& Sons, Ltd; 2012.

5. The international lymphoedema framework. Best practice for the management of lymphoedema - 2nd edition.

6. Brizzio E, Amsler F, Lun B, Blättler W. Comparison of low-strength compression stockings with bandages for the treatment of recalcitrant venous ulcers. J Vasc Surg. 2010;51(2):410-416.

7. Milic DJ, Zivic SS, Bogdanovic DC, et al. The influence of different sub-bandage pressure values on venous leg ulcers healing when treated with compression therapy. J Vasc Surg. 2010;51(3):655-661.

8. Partsch H, Clark M, Bassez S, et al. Measurement of lower leg compression in vivo: recommendations for the performance of measurements of interface pressure and stiffness: consensus statement. Dermatol Surg. 2006;32(2):224-232; discussion 233.

9. Al Khaburi J, Dehghani-Sanij AA, Nelson EA, Hutchinson J. Effect of bandage thickness on interface pressure applied by compression bandages. Med Eng Phys. 2012;34(3):378-385.

10. Thomas S. The use of the Laplace equation in the calculation of sub-bandage pressure. Eur Wound Manag Assoc. 2003;(3):21-23.

11. Damstra RJ, Partsch H. Prospective, randomized, controlled trial comparing the effectiveness of adjustable compression Velcro wraps versus inelastic multicomponent compression bandages in the initial treatment of leg lymphedema. J Vasc Surg Venous Lymphat Disord. 2013;1(1):13-19.

12. Danielsen L, Munk Madsen S, Henriksen L, Sindrup J, Petersen LJ. Subbandage pressure measurements comparing a long-stretch with a short-stretch compression bandage. Acta Derm Venerol. 1998;78:201-204.

13. Mosti G, Partsch H. Bandages or Double Stockings for the Initial Therapy of Venous Oedema? A Randomized, Controlled Pilot Study. Eur J Vasc Endovasc Surg. 2013;46(1):142-148.

14. Partsch H, Mosti G. Comparison of three portable instruments to measure compression pressure. Int Angiol. 2010;29(5):426-430. 
15. Mosti G, Partsch H. Inelastic bandages maintain their hemodynamic effectiveness over time despite significant pressure loss. J Vasc Surg. 2010;52(4):925-931.

16. Huston RL. Principles of Biomechanics. Boca Raton: CRC Press; 2009.

17. Coull A, Tolson D, McIntosh J. Class-3c compression bandaging for venous ulcers: comparison of spiral and figure-of-eight techniques. $J$ Adv Nurs. 2006;54(3):274-283.

18. Hirai $\mathrm{M}$, Niimi $\mathrm{K}$, Iwata $\mathrm{H}$, et al. A comparison of interface pressure and stiffness between elastic stockings and bandages. Phlebology. 2009;24(3):120-124.

19. Benigni JP, Uhl JF, Cornu-Thénard A, Blin E. Compression bandages: influence of techniques of use on their clinical efficiency and tolerance. Int Angiol. 2008;27(1):68-73.

20. Rimaud D, Convert R, Calmels P. In vivo measurement of compression bandage interface pressures: The first study. Ann Phys Rehabil Med. 2014;57(6-7):394-408.

21. Lattimer CR, Kalodiki E, Kafeza M, Azzam M, Geroulakos G. Quantifying the Degree Graduated Elastic Compression Stockings Enhance Venous Emptying. Eur J Vasc Endovasc Surg. 2014;47(1):75-80.

22. Mosti G, Partsch H. Improvement of Venous Pumping Function by Double Progressive Compression Stockings: Higher Pressure Over the Calf is More Important Than a Graduated Pressure Profile. Eur J Vasc Endovasc Surg. 2014;47(5):545-549.

23. Bhattacharya S, Shaikh T, Purushottam Solao R. Development of prototype bandage lapper for constant tension bandaging required for effective medicalclinical treatments. J Tissue Viability. 2012;21(2):54-63.

24. Hafner J, Lüthi W, Hänssle H, Kammerlander G, Burg G. Instruction of Compression Therapy by Means of Interface Pressure Measurement. Dermatol Surg. 2000;26(5):481-488.

25. Thomas S, Fram P. Laboratory-based evaluation of a compression-bandaging system. Nurs Times. 2003;99(40):24-28.

26. Raj TB, Goddard M, Makin GS. How long do compression bandages maintain their pressure during ambulatory treatment of varicose veins? $\mathrm{Br} J$ Surg. 1980;67(2):122-124.

27. Hanna R, Bohbot S, Connolly N. A comparison of inferface pressures of three compression bandage systems. Br J Nurs Mark Allen Publ. 2008;17(20):S16-S24.

28. Mosti G, Mattaliano V. Simultaneous changes of leg circumference and interface pressure under different compression bandages. Eur J Vasc Endovasc Surg. 2007;33(4):476-482.

29. Partsch $\mathrm{H}$. The use of pressure change on standing as a surrogate measure of the stiffness of a compression bandage. Eur J Vasc Endovasc Surg. 2005;30(4):415421.

30. Partsch H. The static stiffness index: a simple method to assess the elastic property of compression material in vivo. Dermatol Surg. 2005;31(6):625-630. 
510 31. Thomas S. Practical limitations of two devices used for the measurement of subbandage pressure: Implications for clinical practice. $J$ Wound Care. 2014;23(6):300-313. 


\section{$514 \quad$ List of tables}

515 Table 1 : Mechanical properties of the two bandages used for the pressure

516 measurements

517 Table 2 : Age and morphological data (circumferences at measurement points B1 and

518 C) of the subjects 


\section{$519 \quad$ List of figures}

520 Figure 1: Location of measurement points B1 (where the Achilles' tendon turns into the

521 gastrocnemius muscle) and $\mathrm{C}$ (where the calf circumference is the largest)

522 Figure 2 : Bandage stretch and application technique in the form of a spiral; A visual

523 marker (a rectangle which turns into a square when the bandage stretch is about 1.3)

524 helps to apply the bandage with the correct stretch; Lines are drawn to help to apply the

525 bandage with the correct overlap

526 Figure 3: Bandage applied in the form of a spiral with a 50\% (a) or $66 \%$ (b)

527 overlapping technique and locations of the sensors (c)

528 Figure 4: Stretch of the applied bandages (a) and mean pressure values (in the supine

529 position) at measurement point B1 for the different bandages (b)

530 Figure 5: Evaluation of the influence on the applied pressure of the bandage mechanical

531 properties (a), application technique (b), and position (d) considering both measurement

532 points; Evaluation of the pressure difference between measurement points B1 and C (c)

533 Figure 6: Influence of the leg circumference on the interface pressure at point B1 (o :

$534 \mathrm{p}<0.05, *: \mathrm{p}<0.02)-3$ groups of subjects were created regarding their leg

535 circumference at measurement point B1

536 Figure 7: Difference in leg geometry between supine and standing position 
537 Table 1

\begin{tabular}{|c|c|c|}
\hline & $\begin{array}{c}\text { Longitudinal elastic } \\
\text { modulus }\left[\mathbf{N} \cdot \mathbf{m m}^{-\mathbf{1}}\right]\end{array}$ & $\begin{array}{c}\text { Force at stretch }=\mathbf{1 . 3} \\
{\left[\mathbf{N} . \mathbf{m m}^{-\mathbf{1}}\right]}\end{array}$ \\
\hline Biflex $^{\circledR} 16(\mathrm{~B} 16)$ & 0.23 & 0.070 \\
\hline Biflex $^{\circledR} 17$ (B17) & 0.44 & 0.13 \\
\hline
\end{tabular}




\begin{tabular}{|c|c|c|c|}
\hline & Age & Circumference at B1 [cm] & Circumference at C [cm] \\
\hline Women & $41.6 \pm 1.31$ & $31.4 \pm 1.3$ & $36.2 \pm 1.6$ \\
\hline Men & $43.6 \pm 1.12$ & $30.4 \pm 1.2$ & $36.9 \pm 1.4$ \\
\hline
\end{tabular}


539 Figure 8: Location of measurement points B1 (where the Achilles' tendon turns into the

540 gastrocnemius muscle) and $\mathrm{C}$ (where the calf circumference is the largest)

541

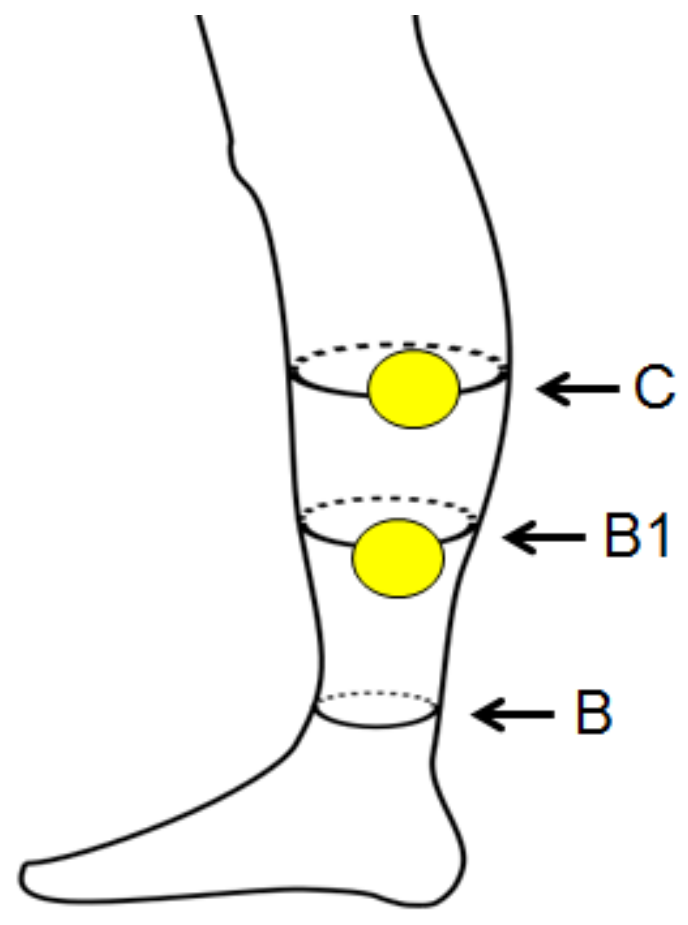


542 Figure 9 : Bandage stretch and application technique in the form of a spiral; A visual

543 marker (a rectangle which turns into a square when the bandage stretch is about 1.3)

544 helps to apply the bandage with the correct stretch; Lines are drawn to help to apply the

545 bandage with the correct overlap

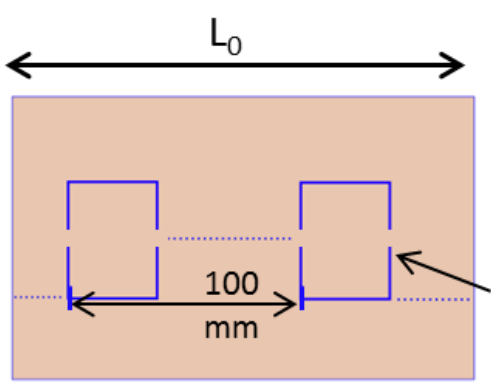

Stretch

calibration marker

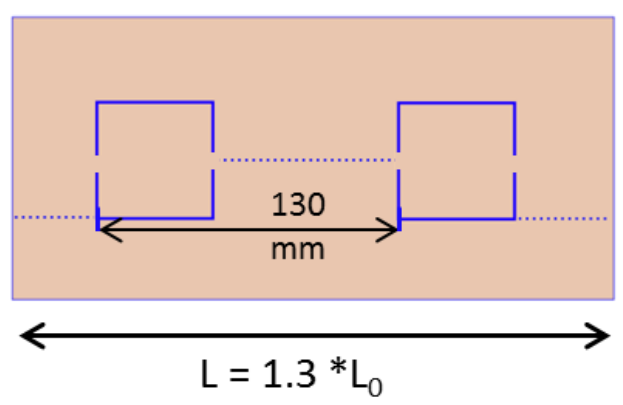

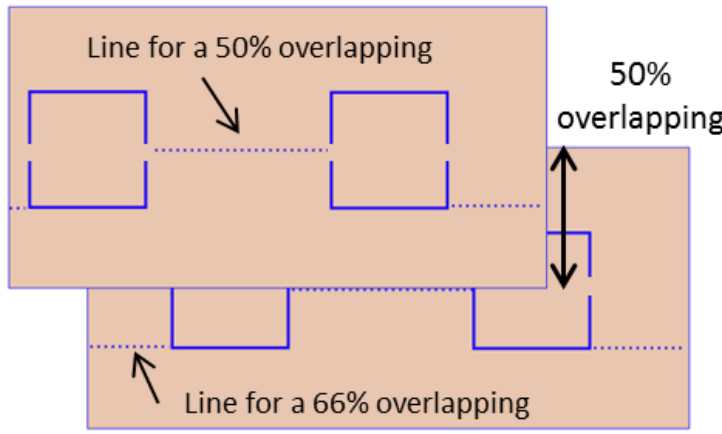

$66 \%$

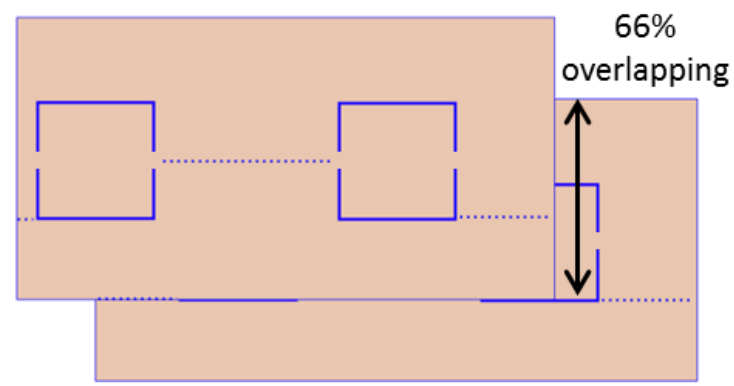


547 Figure 10: Bandage applied in the form of a spiral with a 50\% (a) or $66 \%$ (b)

548 overlapping technique and locations of the sensors (c)

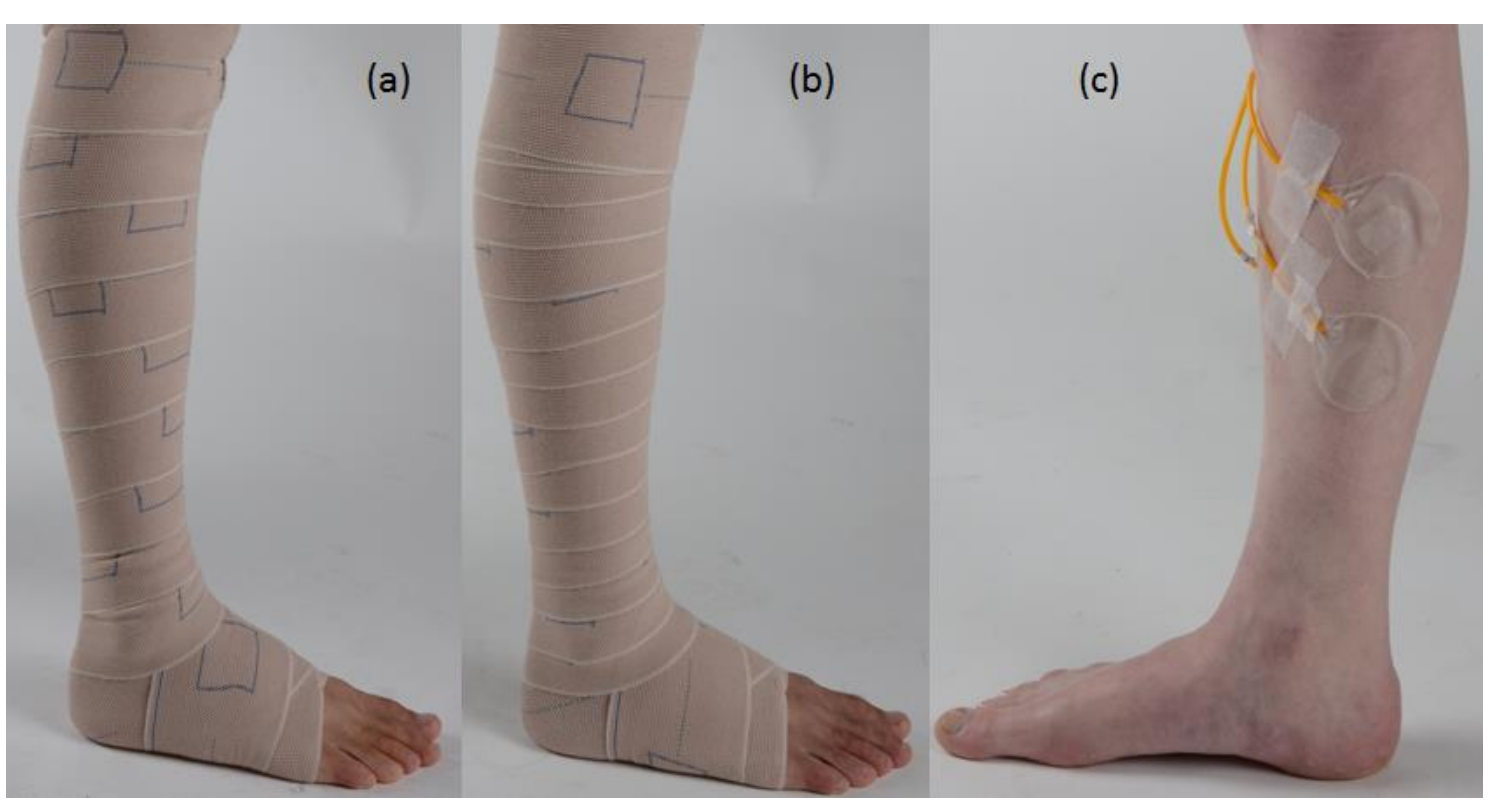


550 Figure 11: Stretch of the applied bandages (a) and mean pressure values (in the supine

551 position) at measurement point B1 for the different bandages (b)

a - Bandage stretch for all application techniques

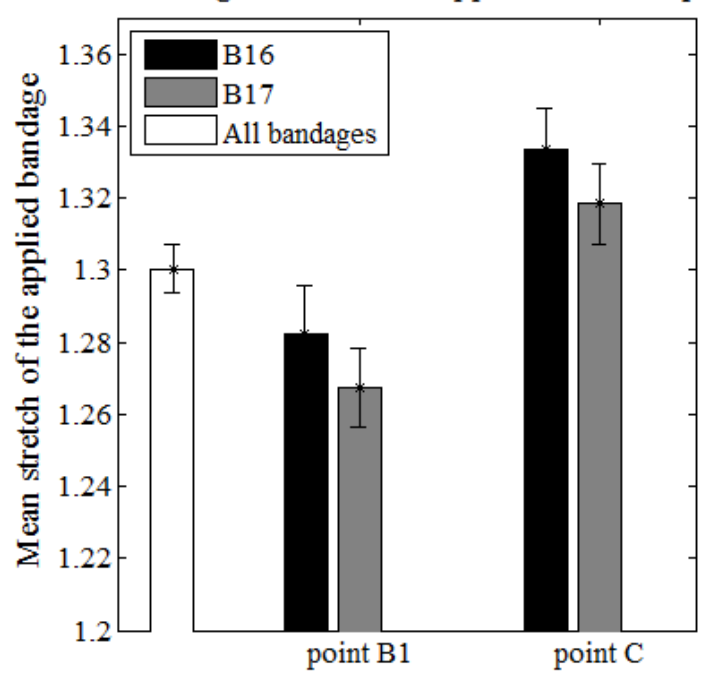

b - Mean pressure values

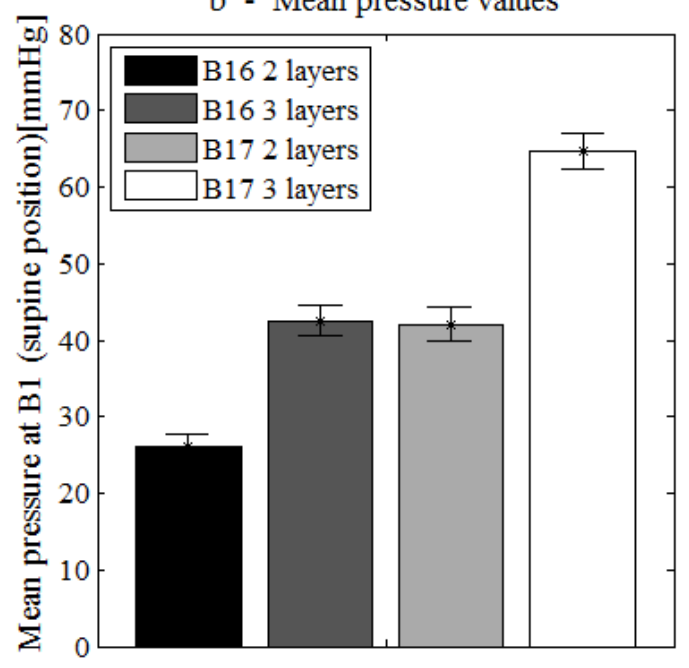

552 

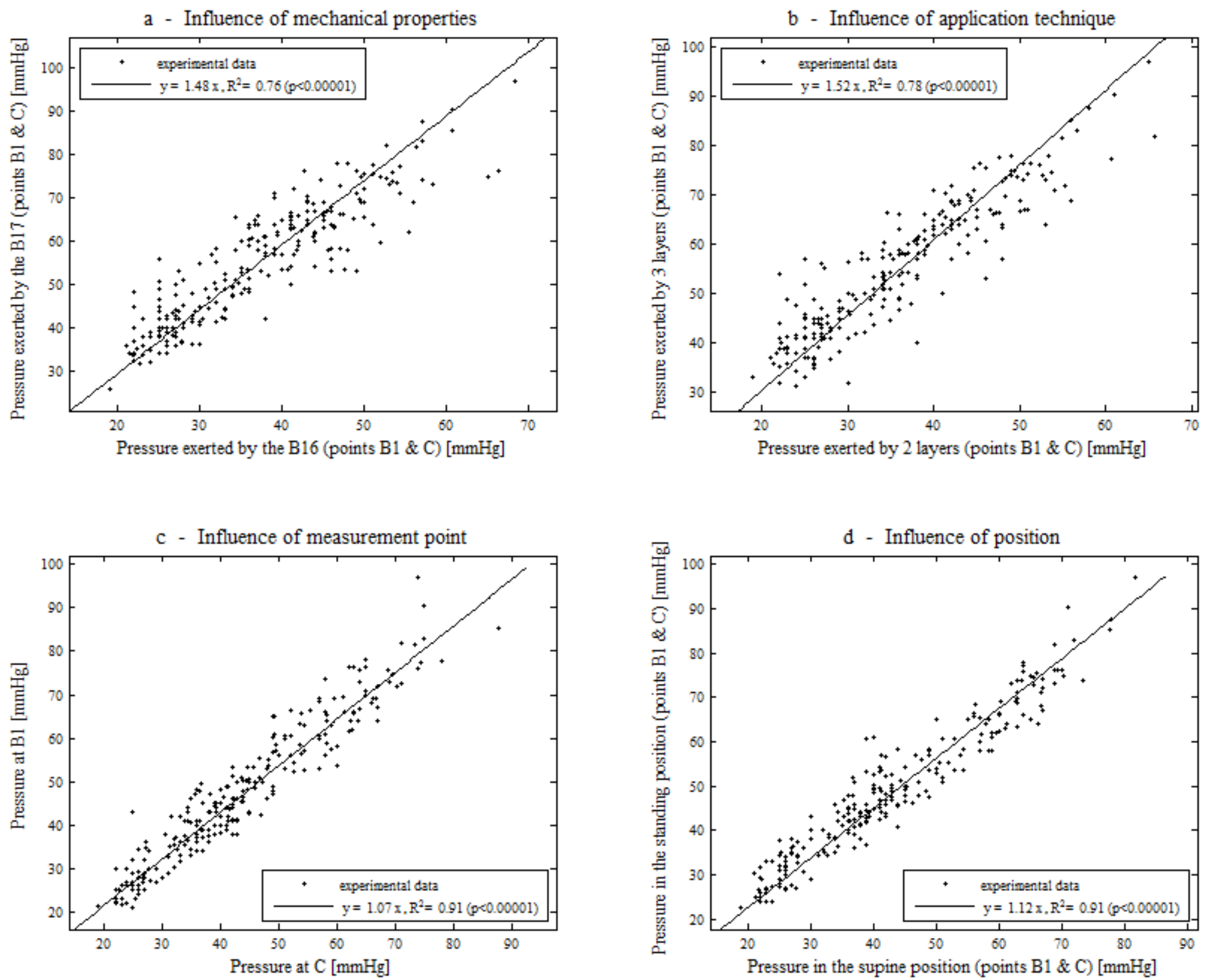
556 Figure 13: Influence of the leg circumference on the interface pressure at point B1 $(\mathrm{o}: \mathrm{p}<0.05, *: \mathrm{p}<$

557 0.02) -3 groups of subjects were created regarding their leg circumference at measurement point B1

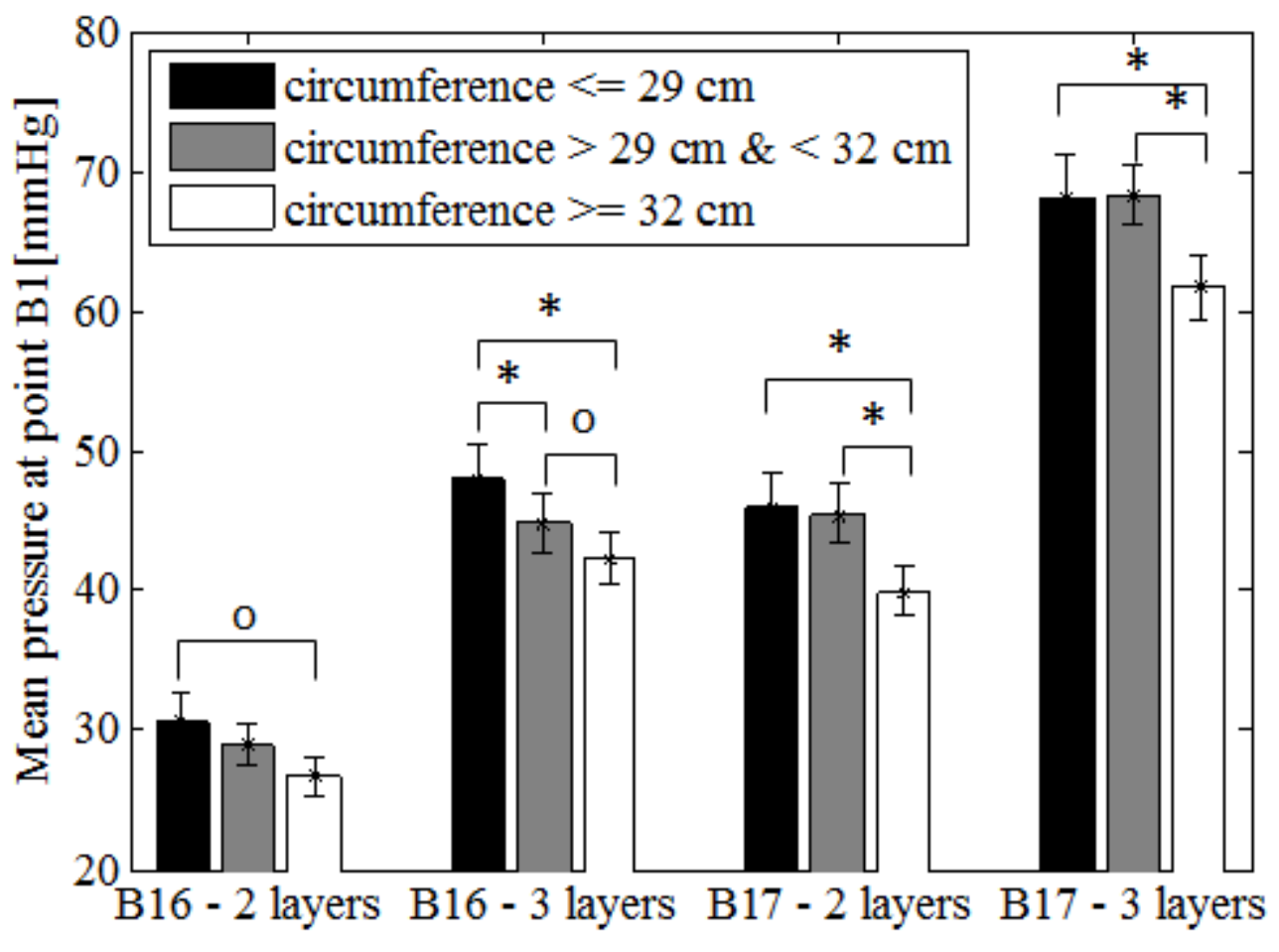


559 Figure 14: Difference in leg geometry between supine and standing position

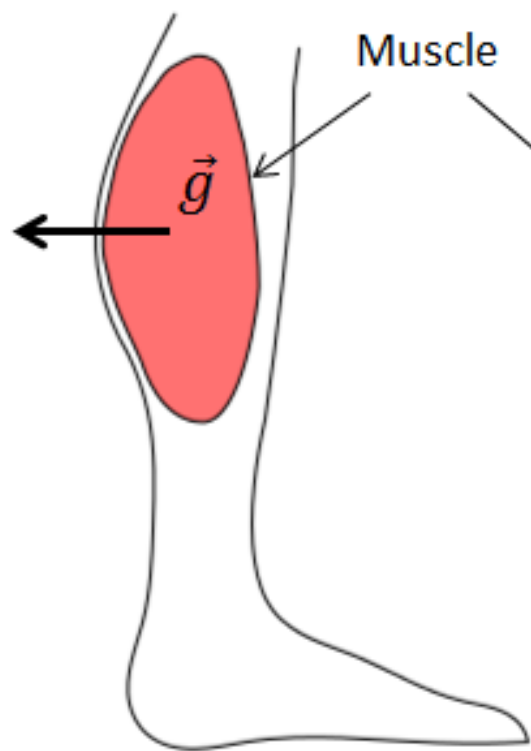

Supine position

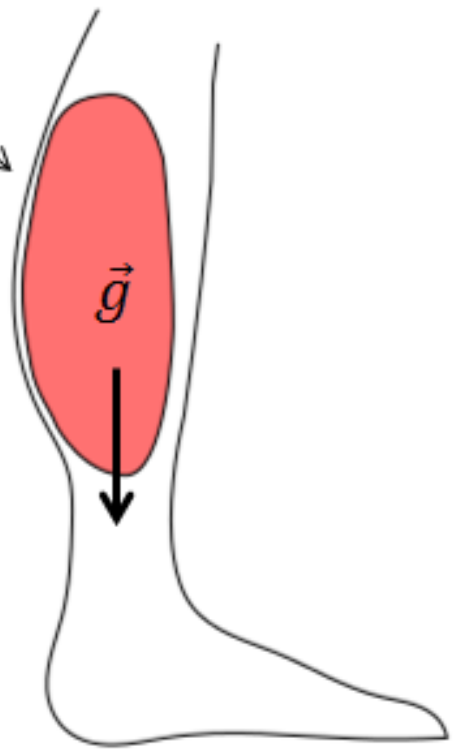

Standing position 